\title{
Renal Expression of Tissue Factor Pathway Inhibitor and Evidence for a Role in Crescentic Glomerulonephritis in Rabbits
}

\author{
Jonathan H. Erlich, ${ }^{\star}$ Jim Apostolopoulos, ${ }^{*}$ Tze-Chein Wun, ${ }^{\ddagger}$ Kuniko K. Kretzmer, ${ }^{\ddagger}$ Stephen R. Holdsworth, ${ }^{\star}$ \\ and Peter G. Tipping* \\ *Centre for Inflammatory Diseases, Department of Medicine, Monash University, Clayton, Victoria, 3168, Australia \\ and ${ }^{\ddagger}$ Searle/Monsanto Corporation, Chesterfield, Missouri 63198
}

\begin{abstract}
Tissue factor pathway inhibitor (TFPI) was demonstrated in the kidneys of normal rabbits and in a crescentic model of glomerulonephritis (GN), where fibrin is a key mediator of injury. In normal kidneys, TFPI was expressed in glomeruli, in intrarenal arteries and the interstitial capillary network. Evidence for TFPI synthesis in vivo was provided by in situ demonstration of TFPI mRNA in glomeruli and intrarenal vessels and by biosynthetic labeling of TFPI released from glomeruli in vitro. In fibrin-dependent crescentic GN, glomerular TFPI synthesis and expression was initially decreased (TFPI antigen at $24 \mathrm{~h}, 7.5 \pm 0.7 \mathrm{ng} / 10^{3}$ glomeruli; normal, $11.1 \pm 0.9 \mathrm{ng} / 10^{3}$ glomeruli, $P<0.02$ ) and subsequently returned to normal values. Plasma TFPI levels increased progressively throughout the evolution of disease. In vivo inhibition of TFPI using an anti-TFPI antibody during the development of GN significantly increased glomerular fibrin deposition (GFD) and exacerbated renal impairment. Infusion of recombinant human TFPI significantly reduced development of GFD (fibrin scores, TFPI treated $0.82 \pm 0.11$, control 1.49 $\pm 0.14, P<0.01)$, proteinuria and renal impairment. This data indicates that TFPI is synthesized and expressed in normal glomeruli and is down regulated in the early response to glomerular injury. Endogenous glomerular TFPI and treatment with recombinant TFPI reduces GFD and injury in fibrin dependent GN. TFPI has the potential to be of therapeutic benefit in the management of fibrin dependent human GN. (J. Clin. Invest. 1996. 98:325335.) Key words: kidney • capillary • fibrin • tissue factor • procoagulant activity $\bullet$ coagulation
\end{abstract}

\section{Introduction}

Tissue factor pathway inhibitor (TFPI) ${ }^{1}$ is the naturally occurring inhibitor of tissue factor (TF), the major in vivo activator of the coagulation cascade $(1,2)$. TFPI is thought to inhibit TF/ VIIa activity in a two step reaction. First TFPI binds and inhibits factor $\mathrm{Xa}$, then the TFPI/Xa complex binds to TF/VIIa resulting in inhibition of TF/VIIa activity $(3,4)$. In humans, TFPI exists free in the circulation and also in association with lipo-

Address correspondence to Dr. P. Tipping, Department of Medicine, Monash Medical Centre, 246 Clayton Road, Clayton, Victoria, 3168, Australia. Phone: 39550 5547; FAX: 395505524.

Received for publication 3 September 1995 and accepted in revised form 1 May 1996.

J. Clin. Invest.

(C) The American Society for Clinical Investigation, Inc.

0021-9738/96/07/0325/11 \$2.00

Volume 98, Number 2, July 1996, 325-335 proteins and in platelets. The major pool of TFPI is on the surface of endothelial cells $(1,5)$. In rabbits, TFPI is not lipoprotein bound and plasma TFPI has a molecular weight between 43 and $45 \mathrm{kD}(6,7)$. TFPI bound to endothelial cells may play a critical role in controlling factor Xa generation and coagulation at sites of local endothelial cell injury.

TFPI synthesis by endothelial cells in vitro does not appear to be regulated by proinflammatory cytokines such as interleukin 1 (IL-1) and tumor necrosis factor- $\alpha$ (TNF $\alpha)$ (8), which regulate $\mathrm{TF}$ and plasminogen activator inhibitor-1 (PAI-1) production. In vivo, in both humans and rabbits, TFPI on endothelial cells is released from glycosaminoglycan binding sites by heparin $(9,10)$, however few factors which regulate the synthesis of TFPI have been identified. Evidence for a functional role for TFPI in vivo has been provided by experimental studies. In rabbits, immunological inhibition of TFPI results in sensitization to the effects of systemically administered TF (6) and endotoxin (11). When administered at pharmacological doses, in short term models, TFPI inhibits thromboplastin induced intravascular coagulation in rabbits (12) and reduces mortality from endotoxemia in baboons (13).

The renal expression of TFPI has not been fully characterized. A single previous report described TFPI expression limited to the microvasculature of the renal cortex (14). The expression of TFPI in glomeruli and its regulation in vivo remain undefined. Changes in the local expression of TFPI has the potential to ameliorate or exacerbate local fibrin deposition resulting from trauma or inflammation. The glomerulus is a high flow vascular bed which is vulnerable to injury by fibrin (15, 16). This is particularly evident in rapidly progressive crescentic forms of GN, where defibrination has been demonstrated to provide significant protection from injury $(17,18)$. The glomerular expression of TFPI may be critical in determining the outcome of fibrin dependent renal injury. To address this issue, the expression of TFPI in the normal kidney and in a crescentic model of fibrin dependent GN was studied in rabbits.

\section{Methods}

Animals. Male New Zealand White rabbits weighing 1.8-2.5 kg were obtained from Monash University Central Animal Services (Clayton, Victoria, Australia).

Production of polyclonal and monoclonal antibodies to rabbit TFPI. Recombinant rabbit TFPI was produced by expression of rabbit TFPI cDNA in E. coli, refolding and ion-exchange chromatography using the same protocol as that described for the production of

1. Abbreviations used in this paper: anti-GBM GN, anti-glomerular basement membrane antibody induced glomerulonephritis; APPT, activated partial thromboplastin time; GBM, glomerular basement membrane; GN, glomerulonephritis; PT, prothrombin time; rhTFPI, recombinant human tissue factor pathway inhibitor; TF, tissue factor; TFPI, tissue factor pathway inhibitor. 
recombinant human TFPI (19). The recombinant rabbit protein was used to raise monoclonal and polyclonal antibodies to rabbit TFPI. A polyclonal antibody was raised in a sheep by immunization with $50 \mu \mathrm{g}$ of recombinant TFPI in Freund's complete adjuvant (Commonwealth Serum Laboratories [CSL], Parkville, Victoria, Australia) and five subsequent boosts of $25 \mu \mathrm{g}$ of recombinant TFPI in Freund's incomplete adjuvant (CSL). Sheep plasma was absorbed against rabbit red blood cells and a globulin fraction was prepared by ammonium sulphate precipitation and dialyzed against PBS. The antibody was a potent inhibitor of rabbit TFPI in a two stage chromogenic assay for TFPI activity and recognized a $45-\mathrm{kD}$ protein in rabbit plasma on Western blotting. This corresponds to the previously reported molecular weight of rabbit plasma TFPI (6). This antibody was subsequently used in a TFPI ELISA and for in vivo inhibition.

To raise monoclonal antibodies, Balb/c mice were immunized with $10 \mu \mathrm{g}$ of purified TFPI in Freund's complete adjuvant and their spleen cells were fused with NS1 cells to produce hybridomas by standard techniques. Supernatants from clones were screened for TFPI reactivity using recombinant antigen coated on microtiter plates. The monoclonality of reactive clones was ensured by subcloning at limiting dilution on two occasions. A number of monoclonal antibodies were produced which detected a $45-\mathrm{kD}$ protein in rabbit plasma and in conditioned medium from rabbit aortic endothelial cells. One clone produced an IgG1 antibody which inhibited TFPI activity in a functional two stage chromogenic assay (6). This antibody was used in an ELISA and for subsequent immunohistochemical studies.

Demonstration of TFPI antigen by immunoperoxidase. Four $\mu \mathrm{m}$ sections of snap frozen renal cortex were fixed for $30 \mathrm{~s}$ in $70 \%$ ethanol and stained with monoclonal anti-TFPI antibody $(20 \mu \mathrm{g} / \mathrm{ml})$. Glomerular endothelial cells were demonstrated using a specific monoclonal anti-rabbit endothelial cell antibody (EC-1, a gift of Dr. S. Kloth, Regensburg, Germany) (20) on cryostat-cut, acetone fixed tissue sections. Glomerular visceral epithelial cells (podocytes) were demonstrated using a monoclonal antibody to rabbit GLEPP-1, a specific marker of podocytes (provided by Dr. R. Wiggins, Ann Arbor, MI) (21) on $2 \mu \mathrm{m}$ formalin fixed, paraffin embedded tissue sections. Irrelevant isotype matched monoclonal antibodies at identical dilutions were used to assess non-specific staining. A peroxidase antiperoxidase technique, previously used on kidney tissue (21), was employed to detect the primary antibodies.

Demonstration of TFPI production in vitro. Glomerular TFPI production in vitro was demonstrated by immunoprecipitation of biosynthetically labeled protein in conditioned medium from cultured normal glomeruli. Renal cortical tissue was collected aseptically and glomeruli isolated by graded sieving as previously described (23). Isolated glomeruli were washed once in PBS and then in methionine and cysteine free RPMI 1640 medium (ICN Biomedicals Inc., Costa Mesa, CA) and then cultured at $5 \times 10^{3} / \mathrm{ml}$ in cystine and methionine free RPMI 1640 with $0.25 \mathrm{mCi}$ of ${ }^{35} \mathrm{~S}$-labeled methionine and cysteine (Amersham, Sydney, Australia). Culture supernatants were sampled at 1,3 and $18 \mathrm{~h}$ and subsequently immunoprecipitated using polyclonal anti-rabbit recombinant TFPI or normal sheep globulin bound to Affi-15 gel (BioRad, Richmond, CA). Bound proteins were eluted by boiling the beads in SDS sample buffer containing $50 \mathrm{mM}$ DTT (BioRad), subjected to SDS PAGE and then transferred onto nitrocellulose. Bound radioactivity was detected by scanning in a Fuji BioImaging BAS1000 phosphoimager.

Measurement of TFPI antigen in glomerular lysates and plasma. TFPI antigen was measured in a sandwich ELISA using a monoclonal capture antibody and a polyclonal detecting antibody. Monoclonal anti-rabbit TFPI antibody was bound to polyvinyl chloride microtiter plates (Dynatech, Chantilly, VA) at a concentration of $4 \mu \mathrm{g} / \mathrm{ml}$ in $0.1 \mathrm{M}$ bicarbonate buffer, $\mathrm{pH} 9.5$ at $4^{\circ} \mathrm{C}$, overnight. Plates were blocked with $3 \%$ nonfat milk powder in PBS and washed twice with PBS. Glomerular lysates were incubated in a final concentration of $2 \%$ Triton X-100 and $0.5 \%$ BSA in Tris-saline for $4 \mathrm{~h}$ at $4^{\circ} \mathrm{C}$. The samples were spun at 2,000 $\mathrm{g}$ for $5 \mathrm{~min}$ and $100 \mu \mathrm{l}$ of the supernatant diluted to a final concentration of $1 \%$ Triton X-100, $0.5 \%$ BSA in Tris-saline and varying concentrations of rabbit recombinant TFPI standard were incubated in wells, overnight at $4^{\circ} \mathrm{C}$. Plates were washed three times in PBS with $0.1 \%$ Tween-20 (PBST) and then incubated with $100 \mu \mathrm{l}$ of sheep anti-rabbit TFPI serum $(5 \mu \mathrm{g} / \mathrm{ml})$ in PBST containing $0.5 \%$ BSA and $1 \%$ nonfat milk powder for $2 \mathrm{~h}$ at room temperature. After three further washes, horseradish peroxidase conjugated donkey anti-sheep IgG serum (Silenus, Hawthorn, Victoria, Australia) was added to the wells at a dilution of 1 in 4000 and incubated for $1 \mathrm{~h}$ at room temperature. The plates were again washed three times and incubated with $0.1 \mathrm{M}$ 2,2'azino-di-3ethlybenzthiazoline sulphonate (ABTS, Boehringer Mannheim, Sydney, Australia) in $0.02 \% \mathrm{H}_{2} \mathrm{O}_{2}$. After $20 \mathrm{~min}$, the absorbance at $405 \mathrm{~nm}$ was read in a microtiter plate reader (MR 7000, Dynatech) and the concentrations of the unknowns were calculated by reference to a standard curve. All standards and samples were assayed in duplicate and the sensitivity of the assay for purified TFPI was $<100 \mathrm{pg} / \mathrm{ml}$. The results were expressed as $\mathrm{ng} / 10^{3}$ glomeruli. Plasma TFPI samples were assayed at a final of dilution of 1 in 50 and the standards for these assays were diluted in a 1 in 50 dilution of human TFPI depleted plasma (American Diagnostica, Greenwich, CT).

Plasma levels of recombinant human TFPI in rabbits receiving TFPI infusions were assayed using a two site ELISA for human TFPI (American Diagnostica). The assay was performed according to the manufacturer's instructions with the following modifications. Plasma samples were assayed at a 1 in 100 dilution in Tris buffered saline $\mathrm{pH}$ 7.5 containing $1 \%$ Triton X-100 to bring the samples into the range of the assay. Standards were diluted in the same buffer.

Analysis of TFPI mRNA. RNA was isolated from rabbit glomeruli by guanidine thiocyanate/ phenol/chloroform extraction as previously described (24), then poly A + RNA was isolated by using a PolyATract mRNA isolating system (Promega, Madison, WI). Northern analysis was performed by electrophoresis of RNA $(5 \mu \mathrm{g}$ per lane) in a $1.2 \%$ agarose gel containing formaldehyde and transferred to nitrocellulose. Slot blot analysis (BioRad) was performed to quantify TFPI mRNA in individual rabbit glomerular samples by application of RNA samples ( $5 \mu \mathrm{g}$ per slot) to nitrocellulose. Nitrocellulose filters were then baked in a vacuum oven at $80^{\circ} \mathrm{C}$ for two hours, then prehydridized at $42^{\circ} \mathrm{C}$. This was followed by hybridization at $80^{\circ} \mathrm{C}$ with a ${ }^{32} \mathrm{P}$-labeled rabbit TFPI cDNA probe, labeled by the "random priming" method (25) then washed as previously described (26). mRNA levels were quantitated by exposing filters in a phosphoimager (Fuji Bio-Imaging BAS1000). Expression of GAPDH mRNA was quantitated using a $330 \mathrm{bp}$ cDNA probe. TFPI mRNA levels in glomeruli during the development of GN was expressed as a percentage of the TFPI mRNA in normal glomeruli after correction for equivalent expression of GAPDH mRNA.

In situ demonstration of TFPI mRNA in kidney sections. In situ hybridization to demonstrate TFPI mRNA was performed on 5- $\mu \mathrm{m}$ frozen tissue sections postfixed in 3\% paraformaldehyde. Sections were prehybridized for $1 \mathrm{~h}$ at $42^{\circ} \mathrm{C}$ in prehybridization solution containing $50 \%$ formamide, $0.75 \mathrm{M}$ trisodium citrate, $0.1 \% \mathrm{PVP}, 0.1 \% \mathrm{BSA}, 50$ $\mathrm{mM} \mathrm{NaH} \mathrm{PO}_{4}$ and $200 \mathrm{mg} / \mathrm{ml}$ sonicated denatured herring sperm DNA (Sigma). Hybridization was performed at $50^{\circ} \mathrm{C}$ overnight with either sense or anti-sense rabbit TFPI cRNA probes $(500 \mathrm{bp})$ labeled in vitro transcription with digoxigenin (Dig-11) dUTP using a Boehringer Mannheim RNA labeling kit. Sections were washed for 15 minutes in $2 \times \mathrm{SSC}$ at room temperature, $15 \mathrm{~min}$ in $1 \times \mathrm{SSC}$ at room temperature, $15 \mathrm{~min}$ in $0.5 \times \mathrm{SSC}$ at $50^{\circ} \mathrm{C}$ then finally for $15 \mathrm{~min}$ in $0.1 \times$ SSC at room temperature. Detection of specific mRNA was accomplished using a sheep anti-Dig alkaline phosphatase antibody (Boehringer Mannheim, Mannheim, Germany) at a dilution of 1 in 5000 in PBS/ $0.5 \%$ Tween 20 , followed by incubation with nitroblue tetrazolium-X phosphate for $1 \mathrm{~h}$. Sections were then counterstained with $1 \%$ methyl-green.

Preparation of anti-GBM globulin and induction of GN. Horse antirabbit GBM antibody was prepared as previously described $(27,28)$. GN was induced by intravenous administration of horse anti-rabbit GBM globulin $(25 \mathrm{mg} / \mathrm{kg})$ to rabbits, presensitized to horse globulin $5 \mathrm{~d}$ 
earlier by subcutaneous injection of horse globulin $(4 \mathrm{mg})$ in Freund's complete adjuvant (CSL). Groups of rabbits killed at $24 \mathrm{~h}$ (day $1, n=$ 13), 96 hours (day $4, n=6)$ and on day $7(n=6)$ after initiation of anti-GBM GN. Normal rabbits $(n=9)$ were age and sex matched. Tissues were analyzed for expression of TFPI antigen and mRNA as described above. Renal histology was assessed on tissue sections fixed in Bouin's fixative, stained with silver methenamine/trichrome. Other indices of injury at these time points in this model, including glomerular crescent formation, fibrin deposition, proteinuria, macrophage infiltration, tissue factor expression and changes in fibrinolytic activity have previously extensively characterized in this model $(27,28)$.

In vivo inhibition of TFPI in anti-GBM GN. Sheep anti-rabbit TFPI serum was absorbed twice with rabbit red blood cells $(10 \%$ by volume) and a globulin fraction was prepared by precipitation with ammonium sulphate at a final concentration of $50 \%$, then extensively dialyzed against PBS. Presensitized rabbits were treated with $(40 \mathrm{mg} /$ $\mathrm{kg})$ sheep anti-rabbit TFPI globulin $(n=7)$ or normal sheep globulin prepared in an identical manner $(n=7) 1 \mathrm{~h}$ prior to induction of GN with anti-GBM globulin as detailed above. Rabbits were then treated with three further doses of anti-rabbit TFPI or normal sheep globulin given at 12 hourly intervals. Renal tissue and blood were collected $48 \mathrm{~h}$ after initiation of GN and urine was collected for the preceding $24 \mathrm{~h}$. Urinary protein excretion ( $24 \mathrm{~h}$ proteinuria) was assayed using the Coomassie blue protein dye binding assay as previously described (28). Creatinine clearance, glomerular fibrin deposition, and hematological and coagulation parameters were assessed as described below.

In vivo infusion of TFPI. Recombinant human (rh) TFPI in urea excipient buffer was prepared as previously described (19). TFPI was prepared in complexes with heparin to maintain its solubility and functional activity throughout the period of the infusion. TFPI/heparin complexes were formed by adding TFPI $(10.0 \mathrm{mg} / \mathrm{ml})$ in urea excipient buffer to porcine mucous heparin sodium (David Bull Laboratories, Melbourne, Victoria, Australia; activity $160 \mathrm{IU} / \mathrm{mg}$ ) in a ratio of 1 to 1.25/TFPI to heparin by weight. Solution for infusion was prepared freshly every $12 \mathrm{~h}$ by diluting the stock solution in sterile PBS to a concentration of $700 \mu \mathrm{g} / \mathrm{ml}$.

Silastic catheters were inserted in the internal jugular veins of rabbits under pentobarbitone anesthesia, $\sim 2 \mathrm{~h}$ before the commencement of the experimental protocol. $30 \mathrm{~min}$ before receiving a subnephritogenic dose of anti-GBM globulin, rabbits $(n=6)$ received a $1 \mathrm{mg}$ bolus of TFPI followed by a constant infusion at a rate of $0.6 \mathrm{ml} / \mathrm{h}(3.3 \mu \mathrm{g} / \mathrm{kg} / \mathrm{per}$ min of TFPI). Control rabbits $(n=6)$ were infused with excipient buffer/heparin in PBS. Treated and control rabbits thus received a loading dose of $200 \mathrm{IU} / \mathrm{kg}$ and a daily infusion of $950 \mathrm{IU} / \mathrm{kg}$ per day of heparin. This dose of heparin has previously been shown to have no affect on GFD or renal failure in anti-GBM GN in rabbits $(29,30)$. Renal tissue and blood were collected $72 \mathrm{~h}$ after initiation of GN and urine was collected for the preceding $24 \mathrm{~h}$. Serum creatinine, glomerular fibrin deposition, proteinuria and coagulation parameters were assessed. At the end of each infusion rabbits were carefully inspected for any evidence of internal hemorrhage. Particular attention was paid to assessing the wounds at the site of insertion of the silastic catheters.

Serum creatinine and creatinine clearance. Serumandurinecreatinines were measured by the alkaline picric acid method using an autoanalyzer (Cobas Bio, Roche Diagnostics, Basel, Switzerland). Creatinine clearance was calculated from the serum and urine creatinines and the urine volume.

Assessment of fibrin deposition by immunofluorescence. $6-\mu \mathrm{m}$ cryostat-cut renal cortical tissue sections were stained with FITC conjugated sheep anti-rabbit fibrinogen antiserum (Research Plus, Bayonne, $\mathrm{NJ}$ ) at a titre of 1:100 to assess the deposition of fibrinogen related antigens within glomeruli. GFD was assessed in a blinded protocol. Only glomeruli cut in or near the equatorial cross section were included and the extent of immunofluorescence staining in glomeruli scored on a scale from 0 (normal) to +3 (fibrin deposition involving greater than two thirds of the glomerular cross section) as previously described $(17,27,31)$. At least 50 glomeruli per animal were scored.
Measurement of glomerular TF activity and hematological parameters. TF activity was measured in isolated glomeruli by a one stage prothrombin assay as previously described (32). Lysates were prepared by sonication and assayed at a dilution of 1 in 10 to 1 in 40 . Hemoglobin, white cell counts and platelet counts were all performed on blood collected into EDTA on a Coulter STKS analyzer (Coulter Electronics, Miami, FL). Measurement of the activated partial thromboplastin time (APTT), prothrombin time (PT) and plasma fibrinogen concentrations were performed on citrated blood specimens using a Electra $1000 \mathrm{C}$ automatic coagulation timer (Medical Laboratory Automation Inc., Pleasantville, NY).

Statistical analysis. Results are expressed as mean \pm SEM and statistical analysis was performed using a Student's unpaired $t$ test for single group comparisons and Fisher's LSD test for multiple group comparisons.

\section{Results}

TFPI expression in the normal kidney. TFPI could be demonstrated in glomeruli and vessels of normal rabbit kidneys by immunoperoxidase staining (Fig. $1 A$ ). No staining was seen using an irrelevant isotype matched monoclonal antibody (Fig. $1 \mathrm{~B}$ ). In glomeruli, TFPI was expressed in the glomerular tuft (Fig. $1 C$ ) in a staining pattern similar to that observed with a specific rabbit endothelial cell marker (EC- 1), (Fig. $1 F$ and $G)$. The pattern of TFPI expression was different to that of GLEPP-1, a marker of glomerular visceral epithelial cells, (Fig. $1 \mathrm{H}$ ). TFPI was not seen in tubules, but was detectable on the endothelium and adventitia of intrarenal arteries (Fig. $1 E$ ) and in the interstitial capillary network (Fig. $1 D$ ).

The presence of TFPI in normal glomeruli was confirmed by extraction and quantitation by immunoassay. In lysates of normal glomeruli, the TFPI content was $11.1 \pm 0.7 \mathrm{ng} / 10^{3}$ glomeruli [gloms]) (Table I). In vitro studies confirmed the capacity of glomeruli to synthesize TFPI. Biosynthetic labeling of TFPI released from normal glomeruli was detectable after $3 \mathrm{~h}$ and strongly evident after $18 \mathrm{~h}$ (Fig. 2). TFPI mRNA with two transcripts of 4.0 and $1.4 \mathrm{~kb}$ was detected in glomeruli by northern blotting (Fig. 3). In situ expression of TFPI mRNA was demonstrated in glomeruli (Fig. $4 \mathrm{~A}$ ) and in the endothelium and adventitia of intrarenal arteries. Hybridization was not detected using the sense probe (Fig. $4 B$ ).

TFPI in fibrin dependent $G N$. Rabbits with anti-GBM GN developed a severe crescentic pattern of renal injury with prominent glomerular fibrin deposition as previously described $(27,28)$. In this model, crescents developing by $4 \mathrm{~d}$ are predominantly fibrinous. Immunohistochemical detection of TFPI demonstrated a decline in glomerular expression 24 hours after initiation of GN (Fig. 1 I), with subsequent return to a similar staining intensity to normal by day 4 (Fig. $1 \mathrm{~J})$. At this time, TFPI was prominent in the glomerular tuft and some areas of weak staining were seen within the fibrinous crescents. TFPI expression in the renal vessels did not appear to change substantially during the evolution of GN.

Glomerular TFPI protein levels measured by ELISA showed similar temporal changes to TFPI antigen detectable by immunostaining. TFPI expression decreased $24 \mathrm{~h}$ after initiation of anti-GBM GN $\left(7.5 \pm 0.7 \mathrm{ng} / 10^{3} \mathrm{glom}, P<0.02 \mathrm{com}-\right.$ pared to normal) and subsequently increased at day 4 $\left(11.2 \pm 0.7 \mathrm{ng} / 10^{3}\right.$ glom, $P=0.002$ compared with day 1$)$ and remained at a similar level on day $7\left(10.2 \pm 1.6 \mathrm{ng} / 10^{3} \mathrm{glom}\right)(\mathrm{Ta}-$ ble I). Plasma TFPI levels progressively rose throughout the 

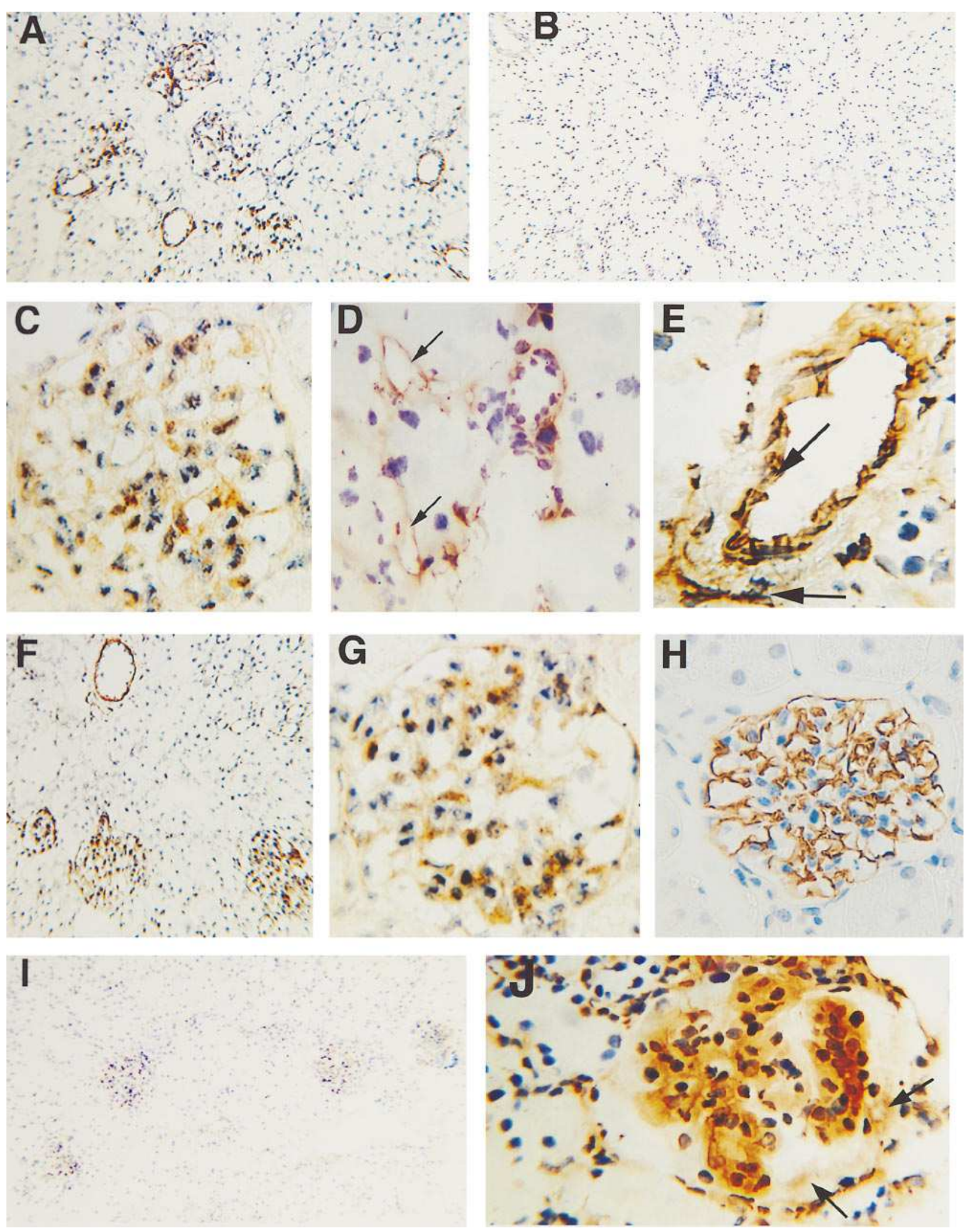

Figure 1. Photomicrographs demonstrating the distribution of TFPI antigen in kidneys by immunoperoxidase staining with a monoclonal antirabbit TFPI antibody $(A-E)$. Staining in a normal kidney demonstrates TFPI expression in glomeruli and intrarenal vessels, but not on parietal aspect of Bowman's capsule or in tubules $(A, \times 100)$. No staining is observed using an irrelevant monoclonal antibody $(B, \times 100)$. At higher magnification, diffuse staining of the glomerular tuft is seen in normal glomeruli in a pattern suggesting endothelial cell expression $(C, \times 400$, compare with $F$ and $G$ ). TFPI is expressed on microvascular endothelium (arrows) in the renal interstitium $(D, \times 400)$ and on the endothelium (arrows) and adventitia (arrows) of intrarenal arteries $(E, \times 400)$. The staining pattern using a specific monoclonal anti-rabbit endothelial cell antibody (EC-1) shows a similar staining pattern to TFPI, both at low power $(F, \times 100)$ and in the glomerulus at higher magnification $(G, \times 400)$. 
Table I. Glomerular TFPI Protein and mRNA and Plasma TFPI during the Development of Anti-GBM GN

\begin{tabular}{|c|c|c|c|c|}
\hline & Normal & Day 1 & Day 4 & Day 7 \\
\hline *TFPI protein (ng/10 glomeruli) & $11.1 \pm 0.7$ & $7.5 \pm 0.7$ & $11.2 \pm 0.7$ & $10.2 \pm 1.6$ \\
\hline ¥TFPI mRNA (percentage of normal glomeruli) & $100 \pm 5.5$ & $68 \pm 4.0$ & $95 \pm 9$ & $88 \pm 9$ \\
\hline${ }^{\S}$ Plasma TFPI $(\mathrm{ng} / \mathrm{ml})$ & $239 \pm 41$ & $397 \pm 51$ & $671 \pm 124$ & $881 \pm 129$ \\
\hline
\end{tabular}

* Glomerular TFPI protein levels were measured by ELISA in lysates of glomeruli from normal rabbits and rabbits 1,4 , and $7 \mathrm{~d}$ after induction of anti-GBM GN. There is a significant decrease in TFPI expression between normal and day $1(P<0.02)$, and a subsequent increase between day 1 and day $4(P<0.002) .{ }^{\ddagger}$ Glomerular TFPI mRNA (levels corrected for GAPDH) showed a significant decrease on day 1 of anti-GBM GN compared with normal $(P<0.004)$ and a subsequent increase on day $4\left(P<0.02\right.$, compared with day1). ${ }^{\S}$ Plasma TFPI protein levels increased significantly from normal to day1 $(P<0.05)$ and day 1 to day $4(P<0.05)$.

time course studied (Table I). Expression of glomerular TFPI mRNA showed parallel changes to those of TFPI protein with a $32 \%$ decrease at day 1 ( $P<0.004$ compared to normal), returning to normal levels at day 4 (Table I). In situ hybridization also demonstrated decreased glomerular TFPI mRNA expression at $24 \mathrm{~h}$ (Fig. $4 \mathrm{C}$ ). At day 4, in situ TFPI mRNA expression (Fig. 4 D) was more prominent than day 1 and similar to the levels in normal glomeruli. TFPI mRNA expression was not observed within crescents or in tubular cells at this time.

In vivo inhibition of TFPI in crescentic fibrin dependent GN. $48 \mathrm{~h}$ after initiation of anti-GBM GN, crescents were not seen in the majority of glomeruli (Fig. $5 \mathrm{~A}$ ), only sparse fibrin deposition was observed (figure $5 \mathrm{~B}$ ) and renal impairment was mild in control rabbits given normal sheep globulin. Treatment with sheep anti-rabbit TFPI antibody resulted in a $54 \pm 8 \%$ decrease in circulating TFPI plasma activity compared to controls $(P<0.05)$ (Table II). Anti-TFPI antibody treated rabbits developed histologically more severe renal injury, with more pronounced crescent formation (Fig. $5 \mathrm{C}$ ) and fibrin deposition (Fig. 5 D). Quantitative analysis demonstrated increased GFD (score 1.47 \pm 0.20 , control $0.67 \pm 0.21, P<0.045$ ) and greater impairment of renal function (creatinine clearance $3.4 \pm 0.8 \mathrm{ml} / \mathrm{min}$, control treatment $13.8 \pm 4.8 \mathrm{ml} / \mathrm{min}, P<0.04$ ) in anti-TFPI antibody treated rabbits compared with controls

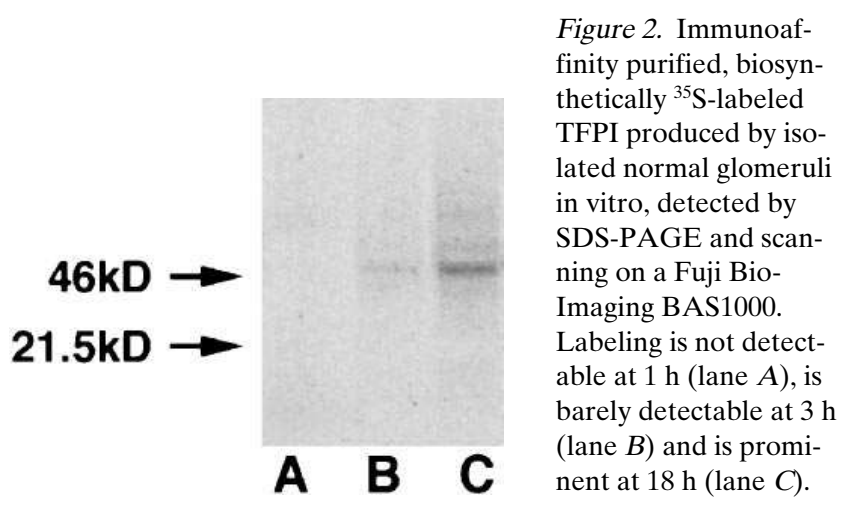

(Fig. 6). Treatment with anti-TFPI antibody also increased glomerular TF activity (anti-TFPI-treated, 15.8 $\pm 6.7 \mathrm{au} / 10^{3}$ gloms, control treatment $5.7 \pm 1.1 \mathrm{au} / 10^{3}$ gloms, $P<0.04$ ) but had no significant effect on the plasma APTT, PT, fibrinogen, hemoglobin, white cell or platelets concentrations (Table II).

In vivo infusion of rhTFPI in crescentic fibrin dependent $G N$. Infusion of rhTFPI resulted in a mean plasma concentration of recombinant human TFPI of $749 \pm 131 \mathrm{ng} / \mathrm{ml}$. rh TFPI was not detectable in animals receiving control infusions. TFPI infusion resulted in a significant reduction in GFD (score $0.82 \pm 0.11$, control $1.49 \pm 0.14, P<0.01)$, proteinuria $(1561 \pm$ $586 \mathrm{mg} / 24 \mathrm{~h}$, control $3176 \pm 432 \mathrm{mg} / 24 \mathrm{~h}, P<0.05)$ and less deterioration in renal function (serum creatinine $129 \pm 22 \mu \mathrm{mol} / \mathrm{l}$, control 323 $\pm 89 \mu \mathrm{mol} / \mathrm{l}, P<0.05$ ) (Fig. 7). Histologically, these rabbits had less severe disease, with less crescent formation (Fig. $8 \mathrm{C}$ ) and less fibrin in glomeruli (Fig. $8 \mathrm{D}$ ) compared to rabbits receiving the control infusions (Fig. $5 \mathrm{E}$ ), which displayed predominantly fibrinous crescents (Fig. $8 \mathrm{~A}$ ) and pronounced fibrin deposition (Fig. 8 B).

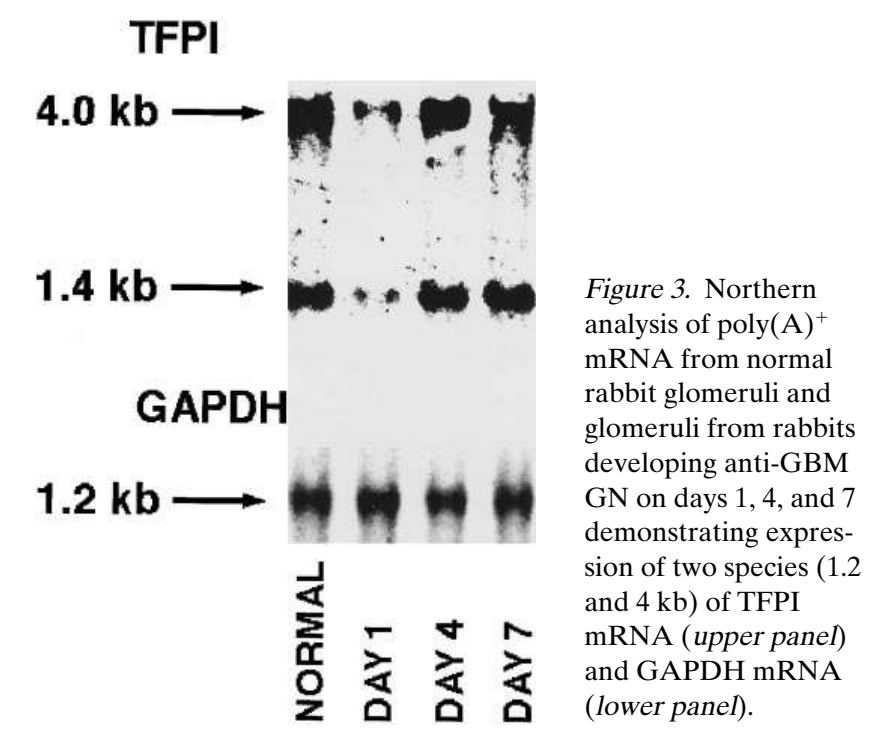

Glomerular staining with a specific marker of rabbit podocytes (GLEPP-1) shows a quite dissimilar staining pattern to TFPI $(H, \times 350)$. Glomerular TPFI expression is downregulated $24 \mathrm{~h}$ after initiation of anti-GBM GN $(I, \times 100) .4 \mathrm{~d}$ after induction of GN, glomerular TFPI is expressed at a similar intensity to normal and is diffusely distributed throughout the glomerular tuft with some weak patchy staining (arrows) within the region of the crescent, expanding Bowman's space $(J, \times 400)$. Crescents were demonstrated to be predominantly fibrinous by staining serial sections for fibrin by direct immunofluorescence. 

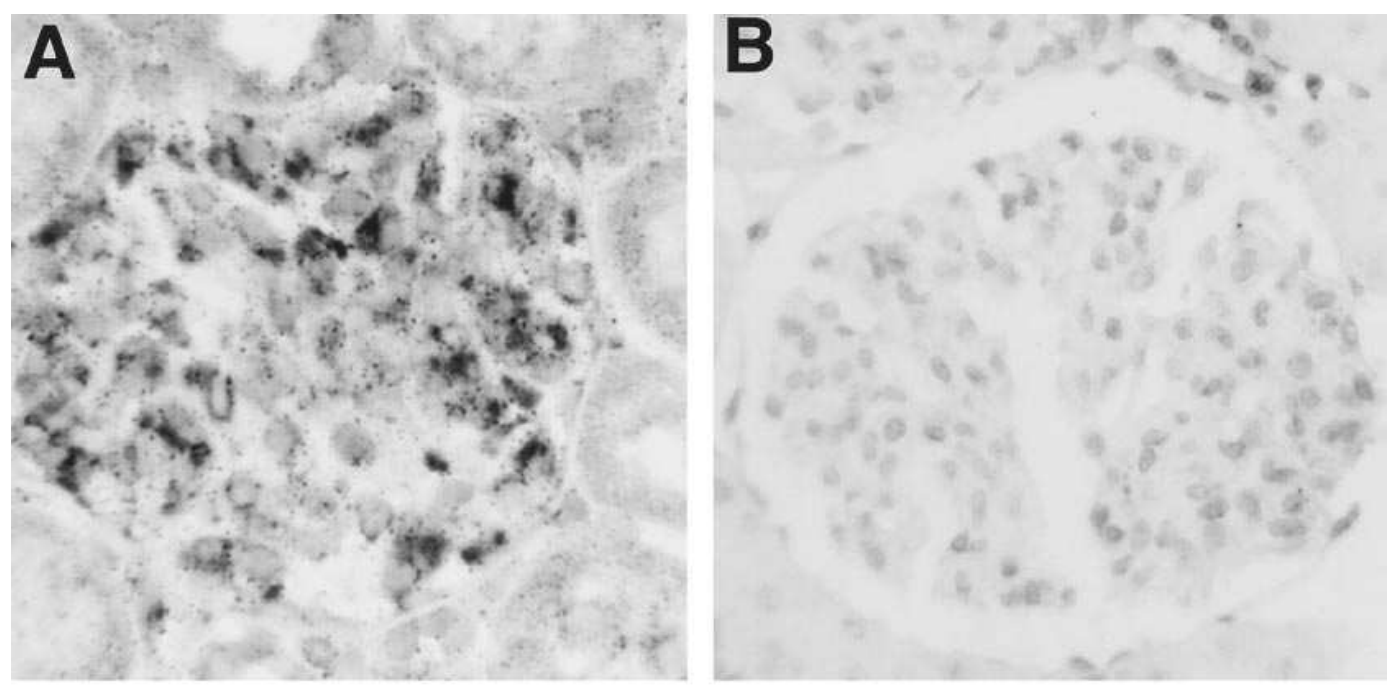

Figure 4. Photomicrographs of rabbit glomeruli demonstrating TFPI mRNA by in situ hybridization using a Dig-labeled probe and alkaline phosphatase reporter system. A strong signal for TFPI mRNA was detected in normal glomeruli with an anti-sense cRNA probe (A) compared with a
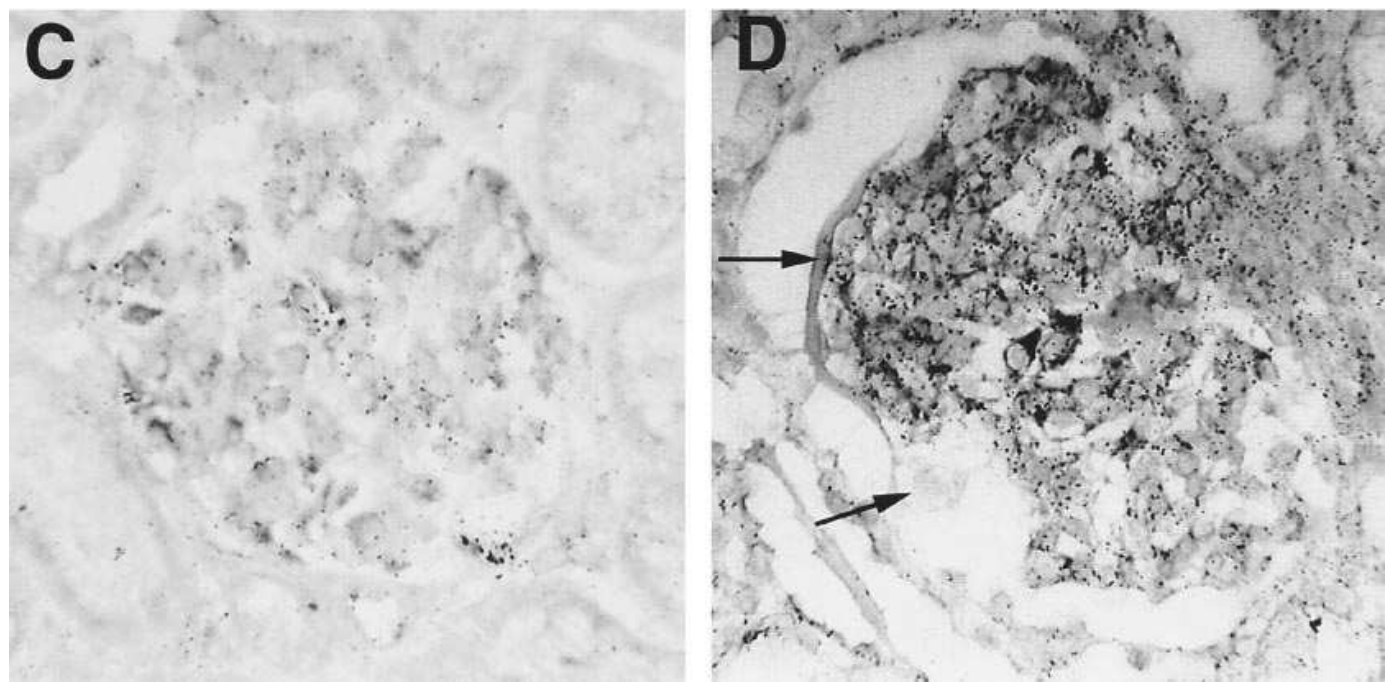
sense cRNA probe control (B). TFPI mRNA was down regulated $24 \mathrm{~h}$ after initiation of antiGBM GN $(C)$; however after $4 \mathrm{~d}(D)$, the pattern and intensity of TFPI mRNA expression in crescentic glomeruli was similar to that of normal glomeruli. Crescents were predominantly fibrinous (demonstrated by staining a serial section by direct immunofluorescence) and hybridization was not detected in the acellular material in Bowman's space (arrows). $\times 320$.

The APTTs of rabbits receiving TFPI/heparin complexes $(36.4 \pm 1.84 \mathrm{~s})$ or control heparin infusion $(38.3 \pm 4.0 \mathrm{~s})$ were 2.1 and 2.2 times control values $(17.4 \pm 0.5 \mathrm{~s})$ respectively, with no significant difference between the groups. The prothrombin times of both groups were normal (TFPI 12.4 $\pm 0.4 \mathrm{~s}$, control $12.3 \pm 1.0 \mathrm{~s}$ ). Plasma fibrinogen levels were also not significantly different between the two groups (TFPI $3.5 \pm 0.32 \mathrm{mg}$ / $\mathrm{ml}$, control $3.4 \pm 0.51 \mathrm{mg} / \mathrm{ml}$ ) but both were higher than normal rabbits $(2.1 \pm 0.1 \mathrm{mg} / \mathrm{ml})$. There was no evidence of bleeding at the site of insertion of the catheters during the infusions and at the end of the experiment detailed macroscopic inspection of the insertion site and internal organs did not reveal any evidence of antemorteum bleeding.

\section{Discussion}

Functionally inhibitory monoclonal and polyclonal antibodies raised against $E$. coli derived recombinant rabbit TFPI were used in this study to develop a sensitive ELISA for measuring rabbit TFPI and techniques for immunolocalization of TFPI. TFPI was detected in glomeruli and in intrarenal arteries and the interstitial capillary network of normal rabbits. In arteries, TFPI expression was seen on the endothelium and in the adventitia. The pattern of staining for TFPI was similar to that of
EC-1, a rabbit endothelial cell marker suggesting that the endothelium is a major site of TFPI binding. This pattern of TFPI staining was different to that of GLEPP 1, a glomerular visceral epithelial (podocyte) marker, suggesting that epithelial cells do not express TFPI. It was not possible to compare the pattern of distribution of TFPI with that of mesangial cells as no specific markers for rabbit mesangial cells are currently available. However, as mesangial cells have been shown to produce TFPI in vitro (33), they may also contribute to the expression of TFPI in normal glomeruli. TFPI was not seen on the parietal epithelium of Bowman's capsule or in renal tubules. These studies confirm the previous studies demonstrating TFPI in the interstitial microvasculature (14) but extend them by demonstrating TFPI in glomeruli and intrarenal arteries.

Studies involving injection of recombinant human TFPI into rabbits have demonstrated that the kidney and liver are major sites of TFPI binding (34). Absence of the COOH-terminal end of the molecule reduces the biological activity of TFPI and results in more renal and less hepatic binding (35). Endothelial cells are thought to be the major site of TFPI synthesis $(8,36)$. Thus, the glomerular expression of TFPI may be the result of local synthesis and/or binding to glomerular endothelium. The detection of TFPI mRNA in glomeruli and the 

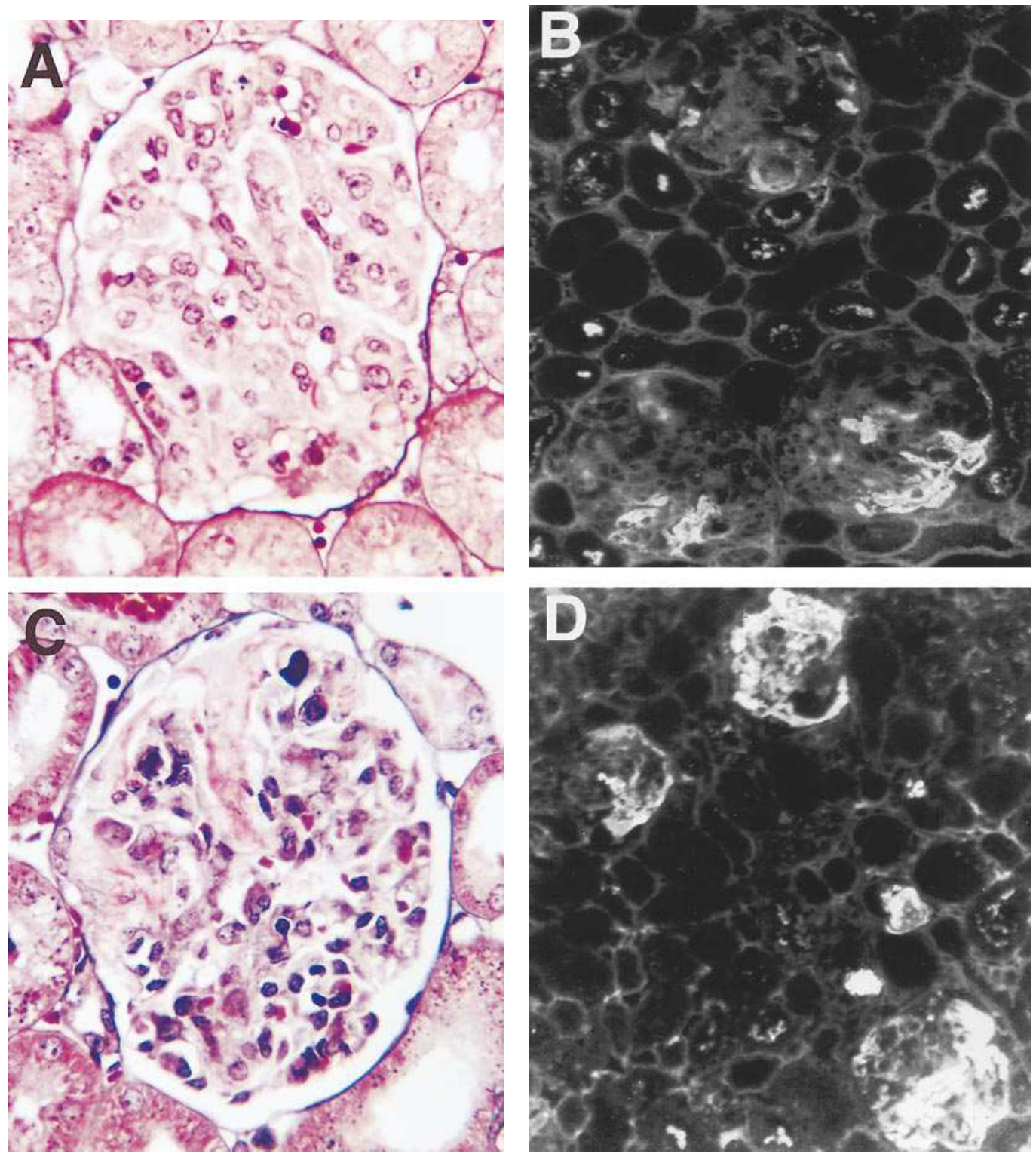

Figure 5. Histological appearances of glomeruli from anti-TFPI antibody treated and control rabbits with anti-GBM GN. 2 d after initiation of $\mathrm{GN}$, rabbits treated with normal sheep globulin showed a proliferative $\mathrm{GN}$ with minimal crescent formation $(A)$ and fibrin deposition $(B)$. In vivo inhibition of TFPI with an anti-TFPI antibody resulted in more pronounced development of crescents $(C)$ and prominent glomerular fibrin deposition $(D)$. ( $A$ and $C$, silver methenamine/ trichrome stain, $\times 400 ; B$ and $D$, fibrin direct immunofluorescence, $\times 100$ ).

demonstration of TFPI synthesis by glomeruli in vitro indicate that local synthesis contributes to glomerular TFPI expression. In fibrin dependent GN, both TFPI protein and mRNA were rapidly down regulated and later returned to normal levels, despite a progressive increase in circulating TFPI levels. The decrease in glomerular TFPI protein and mRNA levels despite an increase in plasma levels further suggests that local synthesis rather than passive endothelial cell binding is the major determinant of glomerular TFPI expression.

Few factors have been identified which regulate endothelial cell TFPI expression. Decreased plasma levels of TFPI have been reported in patients with disseminated intravascular coagulation (37). In vitro, cytokines do not appear to have a consistent effect on TFPI expression and in vivo, regulation of synthesis during inflammatory processes has not been demonstrated (38). Serum or serum supplemented with PMA stimulates endothelial cells to produce TFPI, however proinflammatory cytokines, IL-1, TNF $\alpha$, and LPS had minimal effect (8). Down regulation of glomerular TFPI during the initial stages of fibrin dependent GN provides the first evidence of in vivo regulation of TFPI production.

The factors which direct this initial down regulation remain to be identified. In disseminated intravascular coagulation, changes in plasma TFPI are a part of a systemic dysregulation of coagulation and fibrinolysis, which does not occur in GN. In GN, the changes in glomerular TFPI may reflect glomerular injury, however TFPI expression subsequently returned to normal despite progressive damage suggesting other processes are involved. The later increase in glomerular TFPI protein and mRNA (at day 4) may result from synthesis by infiltrating macrophages, which are prominent at this stage of the disease. Macrophages have been demonstrated to synthesize TFPI in vitro $(38,39)$. Alternatively, glomerular TFPI levels may increase as the result of inflammatory mediators stimulating synthesis by intrinsic glomerular cells.

Despite increasing glomerular injury, glomerular TF activity remains stable between day 1 and 4 in this model (28). The return of normal glomerular TFPI expression over this same 


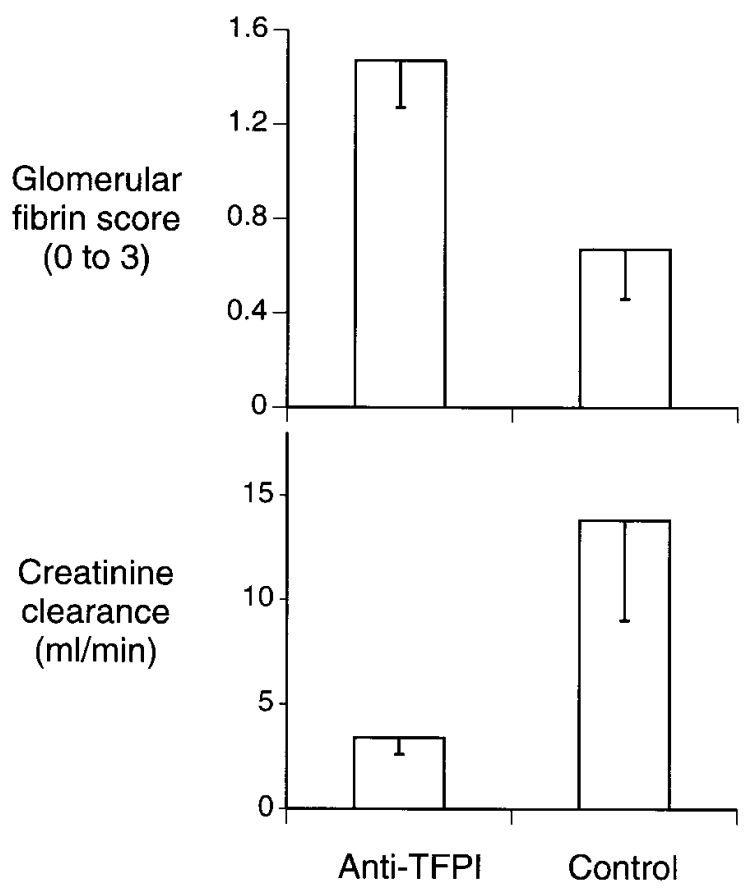

Figure 6. Effect of treatment with anti-TFPI antibody in rabbits developing anti-GBM GN. Fibrin deposition was significantly increased in rabbits treated with anti-TFPI antibody $(P<0.05)$ and their creatinine clearance was significantly lower $(P<0.04)$ indicating more severe renal impairment.

period may contribute to this stabilization of glomerular $\mathrm{TF}$ activity. At this stage in the evolution of the disease, glomerular accumulation of $\mathrm{T}$ cells (40), macrophages (41) and elevated glomerular levels of IL-1(42) and TNF $\alpha$ (43) have been demonstrated. Their contribution to the changes in glomerular TFPI mRNA expression remain to be defined. The late increase in glomerular TFPI mRNA and protein levels in association with fibrin dependent glomerular injury appears to be unique amongst the changes in procoagulant (28) and antifibrinolytic proteins (27) which are all regulated in favor of enhancing coagulation in this model.

The early decrease in glomerular TFPI may account for the dissociation between changes in glomerular TF activity and antigen previously noted in the initial stages of this crescentic model of GN. Within the first $24 \mathrm{~h}$ of disease, glomerular TF activity increases 8.5 -fold while TF protein levels only double (28). Normal glomeruli contain considerable amounts of TF protein $(28,44)$ as well as TFPI. Net TF activity will depend on the relative availability of TFPI to bind and inhibit TF/factor VII complexes as well as negatively charged phospholipids essential for TF function. Local down regulation of TFPI could contribute to the enhanced functional activity of TF and may facilitate early fibrin deposition in crescentic GN.

The functional contribution of TFPI to glomerular fibrin deposition and renal impairment was explored in vivo by inhibition studies using an anti-TFPI antibody. As augmented fibrin deposition and exacerbation of renal injury was anticipated, an early time point at which both parameters were not maximally perturbed was chosen for this study. In vivo administration of TFPI antibody halved the TFPI functional activity in plasma and reduced glomerular tissue factor activity by two
Table II. The Effect of In Vivo TFPI Inhibition on Hematological and Coagulation Parameters in the Blood of Rabbits Developing in Anti-GBM GN

\begin{tabular}{lcc}
\hline & $\begin{array}{c}\text { Anti-TFPI } \\
\text { globulin }\end{array}$ & $\begin{array}{c}\text { Normal sheep } \\
\text { globulin }\end{array}$ \\
\hline Prothrombin time (s) & $7.8 \pm 0.6$ & $8.3 \pm 0.7$ \\
Activated partial thromboplastin & $17.6 \pm 0.8$ & $17.7 \pm 1.5$ \\
$\quad$ time (s) & & \\
Platelet count $\left(\times 10^{9} /\right.$ liter) & $271 \pm 80$ & $247 \pm 78$ \\
White cell count $\left(\times 10^{9} /\right.$ liter) & $14.2 \pm 3$ & $10.2 \pm 2.5$ \\
Hemoglobin (grams/liter) & $9.8 \pm 0.4$ & $9.3 \pm 0.5$ \\
Plasma fibrinogen (grams/liter) & $3.7 \pm 0.5$ & $3.5 \pm 0.4$ \\
* TFPI plasma functional activity & $62 \pm 11^{\ddagger}$ & $136 \pm 18$ \\
$\quad$ (percentage of normal) & & \\
\end{tabular}

* Measured in a two stage chromogenic assay and expressed as a percentage of the activity in normal plasma. ${ }^{\ddagger} \boldsymbol{P}<0.005$ compared with rabbits treated with normal sheep globulin.

thirds. Fibrin deposition, which remained confined to glomeruli, was doubled and impairment of renal function in rabbits treated with anti-TFPI antibodies was markedly exacerbated, confirming the functional importance of fibrin as a mediator of injury in this model. The increased glomerular fibrin deposition was not due to intravascular activation of coagulation as

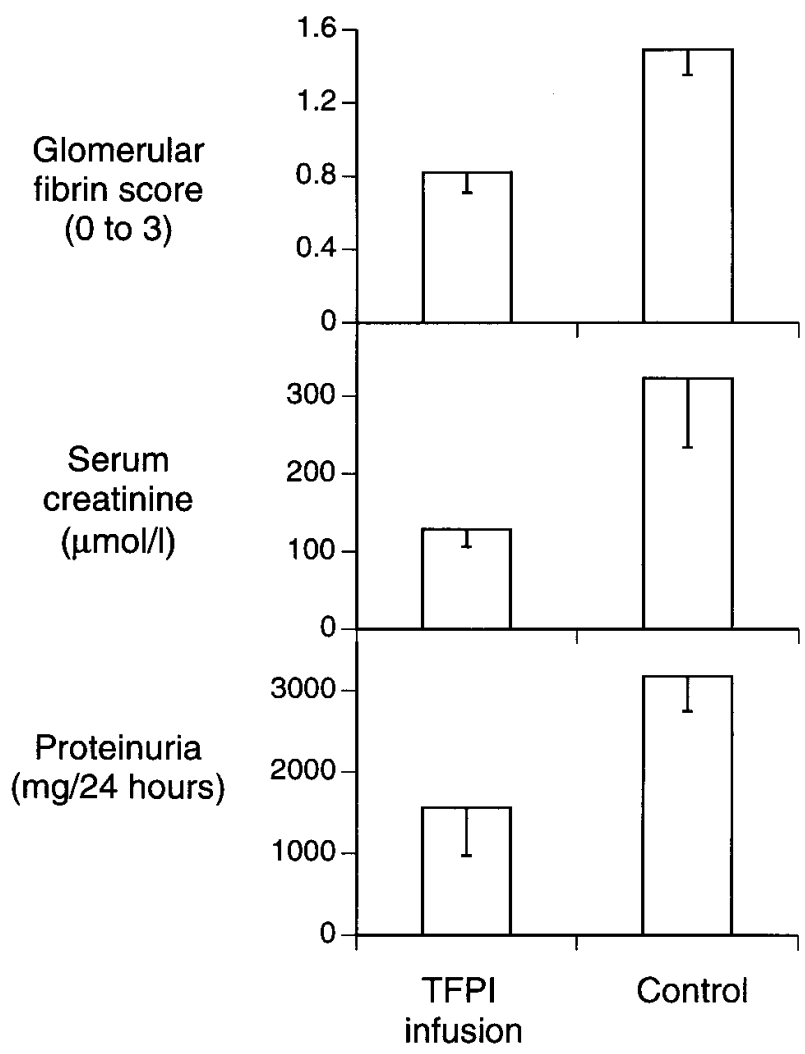

Figure 7. Effect of infusion of human recombinant TFPI on the development of anti-GBM GN. TFPI infused rabbits showed a significant reduction of glomerular fibrin deposition $(P<0.01)$, protection of renal function (significantly lower serum creatinines, $P<0.05$ ) and significantly less proteinuria $(P<0.05)$ when compared with rabbits receiving control infusions. 

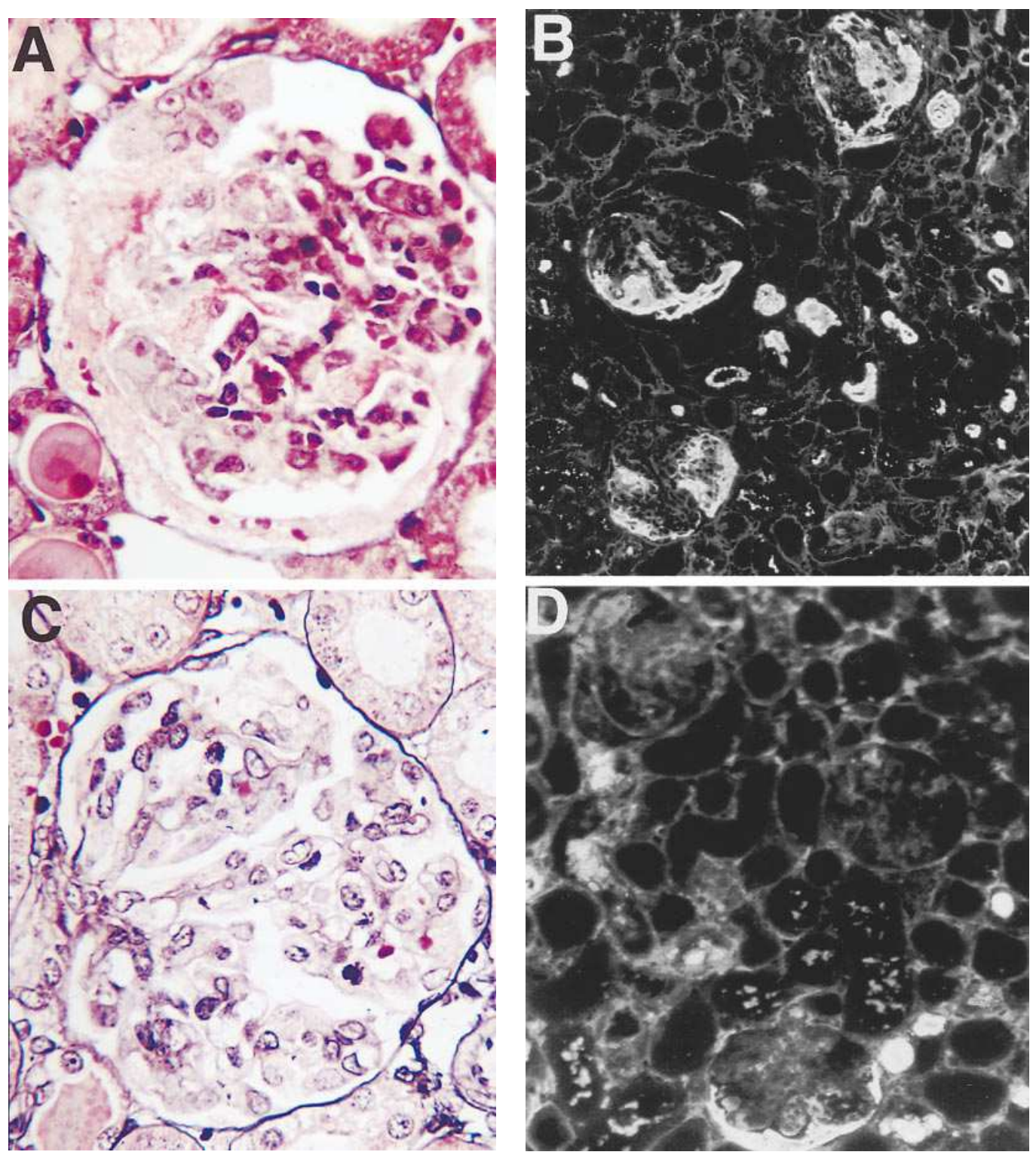

Figure 8. Histological appearances of glomeruli from control treated rabbits with anti-GBM GN and rabbits infused with human recombinant TFPI. $3 \mathrm{~d}$ after initiation of GN, control rabbits developed a crescentic GN $(A)$ with prominent fibrin deposition $(B)$. Rabbits infused with TFPI showed less severe crescent formation $(C)$ and reduced glomerular fibrin deposition $(D)$. ( $A$ and $C$, silver methenamine/ trichrome stain, $\times 300 ; B$ and $D$, fibrin direct immunofluorescence, $\times 75$ ). there were no differences in routine indices of coagulation (PT, APTT, plasma fibrinogen, or platelet counts) between treated and control rabbits. The significant decrease in renal function caused by inhibiting TFPI demonstrates an important role for endogenous TFPI in protecting against glomerular fibrin deposition in crescentic GN.

Infusion of TFPI in experimental disseminated intravascular coagulation (12) and endotoxemia (13) and topical application of TFPI to vascular crush injuries (45) has demonstrated the potential of TFPI to prevent activation of coagulation and subsequent injury, in these short term models involving intravascular coagulation. In the current model of crescentic GN, infusion of recombinant human TFPI was used to explore its potential to inhibit immunologically initiated fibrin deposition developing over several days, predominantly at an extravascular site, i.e., in the glomerular mesangium and in Bowman's space. Continuous infusion of TFPI over a $3 \mathrm{~d}$ period, resulted in significant reduction in glomerular fibrin deposition and proteinuria and protection of renal function.

TFPI was infused complexed with heparin to improve its solubility and functional stability to allow continuous infusion (Wun, T-C., unpublished observations). Infused and control rabbits thus both received a dose of heparin which produced identical prolongation of the APTT in both groups to the lower limit of the therapeutic range and did not result in any abnormal bleeding. The effect of TFPI on the development of fibrin deposition and renal impairment was thus independent of the effect of heparin on the intrinsic coagulation pathway. In two previous studies of heparin in anti-GBM GN in rabbits, doses of heparin larger than used in the current study, had no significant effect on GFD, proteinuria or the development of renal impairment $(29,30)$. Reduction of circulating IL-6 levels by TFPI treatment in $E$. coli induced septicemia (13) suggests it may have a direct anti-inflammatory role. It is possible that this effect may contribute to the reduction of proteinuria observed in crescentic GN in rabbits. The capacity of TFPI to inhibit glomerular fibrin deposition provides strong evidence for a pivotal role of the tissue factor pathway in initiating glomerular fibrin deposition in crescentic GN. It provides further support for the hypothesis that the tissue factor pathway is the ma- 
jor pathway leading to extravascular fibrin deposition during immunologically initiated inflammation.

In summary, TFPI expression in normal kidneys was observed in glomeruli and in intrarenal vessels of all sizes and the ability of glomeruli to synthesize TFPI was demonstrated. Down regulation of TFPI in fibrin dependent, crescentic GN provides the first demonstration of in vivo regulation of TFPI synthesis. This reduction of glomerular TFPI may contribute to the pronounced increase in glomerular TF activity observed early in this disease. Unlike the changes in glomerular expression of procoagulant and fibrinolytic molecules which all favor fibrin deposition in this fibrin dependent model, glomerular TFPI levels return to normal as the disease progressed. An important role for endogenous TFPI in ameliorating glomerular fibrin deposition and injury was demonstrated in crescentic GN. TFPI at pharmacological doses may have a role as a therapeutic agent in fibrin dependent GN. The data suggests that the tissue factor pathway is the main intraglomerular procoagulant pathway, and that inhibition of that pathway may be of therapeutic benefit.

\section{Acknowledgments}

We thank Mr. B. Malepa and Miss. E. Simic for their technical assistance. The monoclonal antibody EC-1 was a gift of Dr. S. Kloth, Regensburg, Germany and anti-GLEPP1 was a gift of Dr. R. Wiggins, Ann Arbor, MI.

These studies were supported by grants from the National Health and Medical Research Council of Australia (NH\&MRC) and the Australian Kidney Foundation. Dr. Tipping is an NH\&MRC Senior Research Fellow, Dr. Apostopopoulos is an NH\&MRC Research Officer, and Dr. Erlich is supported by an NH\&MRC Medical Postgraduate Scholarship.

\section{References}

1. Broze, G.J., Jr. 1992. The role of tissue factor pathway inhibitor in a revised coagulation cascade. Semin. Hematol. 29:159-169.

2. Rapaport, S.I. 1989. Inhibition of factor VIIa/tissue factor-induced blood coagulation: with particular emphasis upon a factor Xa-dependent inhibitory mechanism. Blood. 73:359-365.

3. Broze, G.J., Jr., L.A. Warren, W.F. Novotny, D.A. Higuchi, J.J. Girard, and J.P. Miletich. 1988. The lipoprotein-associated coagulation inhibitor that inhibits the factor VII-tissue factor complex also inhibits factor Xa: insight into its possible mechanism of action. Blood. 71:335-343.

4. Warn-Cramer, B.J., L.V. Rao, S.L. Maki, and S.I. Rapaport. 1988. Modifications of extrinsic pathway inhibitor (EPI) and factor Xa that affect their ability to interact and to inhibit factor VIIa/tissue factor: evidence for a twostep model of inhibition. Thromb. Haemost. 60:453-456.

5. Sandset, P.M., and U. Abildgaard. 1991. Extrinsic pathway inhibitor-the key to feedback control of blood coagulation initiated by tissue thromboplastin. Haemostasis. 21:219-239.

6. Sandset, P.M., B.J. Warn-Cramer, L.V. Rao, S.L. Maki, and S.I. Rapaport. 1991. Depletion of extrinsic pathway inhibitor (EPI) sensitises rabbits to disseminated intravascular coagulation induced with tissue factor: evidence supporting a physiologic role for EPI as a natural anticoagulant. Proc. Natl. Acad. Sci. USA. 88:708-712.

7. Warn-Cramer, B.J., and S.L. Maki. 1992. Purification of tissue factor pathway inhibitor (TFPI) from rabbit plasma and characterisation of its differences from TFPI isolated from human plasma. Thromb. Res. 67:367-83.

8. Ameri, A., M.N. Kuppuswamy, S. Basu, and S.P. Bajaj. 1992. Expression of tissue factor pathway inhibitor by cultured endothelial cells in response to inflammatory mediators. Blood. 79:3219-3226.

9. Sandset, P.M., U. Abildgaard, and M.L. Larsen. 1988. Heparin induces release of extrinsic coagulation pathway inhibitor (EPI). Thromb. Res. 50:803813.

10. Novotny, W.F., S.G. Brown, J.P. Miletich, D.J. Rader, and G.J. Broze, Jr. 1991. Plasma antigen levels of the lipoprotein-associated coagulation inhibitor in patient samples. Blood. 78:387-393.

11. Sandset, P.M., B.J. Warn-Cramer, S.L. Maki, and S.I. Rapaport. 1991. Immunodepletion of extrinsic pathway inhibitor sensitises rabbits to endotoxin- induced intravascular coagulation and the generalised Shwartzman reaction. Blood. 78:1496-1502.

12. Day, K.C., L.C. Hoffman, M.O. Palmier, K.K. Kretzmer, M.D. Huang, E.Y. Pyla, E. Spokas, G.J. Broze, Jr., T.G. Warren, and T-C. Wun. 1990. Recombinant lipoprotein-associated coagulation inhibitor inhibits tissue thromboplastin-induced intravascular coagulation in the rabbit. Blood. 76:1538-1545.

13. Creasey, A.A., A.C. Chang, L. Feigen, T-C. Wun, F.B. Taylor, Jr., and L.B. Hinshaw. 1993. Tissue factor pathway inhibitor reduces mortality from Escherichia coli septic shock. J. Clin. Invest. 91:2850-2856.

14. Werling, R.W., L.R. Zacharski, W. Kisiel, S.P. Bajaj, V.A. Memoli, and S.M. Rousseau. 1993. Distribution of tissue factor pathway inhibitor in normal and malignant human tissues. Thromb. Haemost. 69:366-369.

15. Kincaid-Smith, P. 1972. Coagulation and renal disease. Kidney Int. 2: 183-190.

16. McCluskey, R.T., P. Vasalli, G. Gallo, and D.S. Baldwin. 1966. An immunofluorescent study of pathogenic mechanisms in glomerular disease. $N$. Engl. J. Med. 274:695-701.

17. Tipping, P.G., N.M. Thomson, and S.R. Holdsworth. 1986. A comparison of fibrinolytic and defibrinating agents in established experimental glomerulonephritis. Br. J. Exp. Pathol. 67:481-491.

18. Thomson, N.M., J. Moran, I.J. Simpson, and P.K. Peters. 1976. Defibrination with ancrod in nephrotoxic nephritis in rabbits. Kidney Int. 10:343-347.

19. Diaz-Collier, J.A., M.O. Palmier, K.K. Kretzmer, B.F. Bishop, R.G. Combs, M.G. Obukowicz, R.B. Frazier, G.S. Bild, W.D. Joy, S.R. Hill, M.E. Duffin, M.E. Gustafson, K.D. Junger, R.W. Grabner, G.R. Galluppi, and T.-C. Wun. 1994. Refold and characterisation of tissue factor pathway inhibitor exprssed in Escherichia coli. Thromb. Haemost. 71:339-346.

20. Kloth, S., A. Schmidbauer, M. Kubitza, H.A. Weich, and W.W. Minuth. 1994. Developing renal microvasculature can be maintained under perfusion culture conditions. Eur. J. Cell Biol. 63:84-95.

21. Thomas, P.E., B.L. Wharram, M. Goyal, J.E. Wiggins, L.B. Holzman, and R.C. Wiggins. 1994. GLEPP1, a renal glomerular epilthelial cell (podocyte) membrane protein-tyrosine phosphatase. J. Biol. Chem. 269:19953-19962.

22. Huang, X.R., S.R. Holdsworth, and P.G. Tipping. 1994. Evidence to a role for delayed type hypersensitivity in glomerular crescent formation. Kidney Int. 46:69-78.

23. Holdsworth, S.R., N.M. Thomson, E.F. Glasgow, J.P. Dowling, and R.C. Atkins. 1978. Tissue culture of isolated glomeruli in experimental glomerulonephritis. J. Exp. Med. 147:98-109.

24. Chomczynski, P., and N. Sacchi. 1987. Single step method of RNA isolation by acid guanidinium thiocyanate-phenol-chloroform extraction. Anal. Biochem. 162:156-159.

25. Feinburg, A.P., and B. Vogelstein. 1983. A technique for radiolabeling DNA restriction endonuclease fragments to high specific activity. Anal Biochem. 132:6-13.

26. Apostolopoulos, J., G.J. Howlett, and N. Fidge. 1987. Effects of dietary cholesterol and hypothyroidism on rat apolipoprotein metabolism. J. Lipid Res. 28:642-648.

27. Malliaros, J., S.R. Holdsworth, J. Wojta, J.H. Erlich, and P.G. Tipping. 1994. Glomerular fibrinolytic activity in anti-GBM glomerulonephritis in rabbits. Kidney Int. 44:557-564

28. Tipping, P.G., J. Erlich, J. Apostolopoulos, N. Mackman, D. Loskutoff, and S.R. Holdsworth. 1995. Glomerular tissue factor antigen, activity and mRNA in crescentic glomerulonephritis. Am. J. Pathol. 147:1736-1748.

29. Thomson, N.M., I.J. Simpson, and D.K. Peters. 1975. A quantitative evaluation of anticoagulants in experimental nephrotoxic nephritis. Clin. Exp. Immunol. 19:301-308.

30. Border, W.A., C.B. Wilson, and F.J. Dixon. 1975. Failure of heparin to affect two types of experimental glomerulonephritis in rabbits. Kidney Int. 8: $140-148$.

31. Tipping, P.G., and S.R. Holdsworth. 1986. The participation of macrophages, glomerular procoagulant activity and Factor VIII in glomerular fibrin deposition: studies in anti-glomerular base membrane antibody induced glomerulonephritis in rabbits. Am. J. Pathol. 124:10-17.

32. Tipping, P.G., L.A. Worthington, and S.R. Holdsworth. 1987. Quantitation and characterisation of glomerular procoagulant activity in experimental glomerulonephritis. Lab. Invest. 56:155-159.

33. Yamabe, H., H. Osawa, H. Inuma, M. Kaizuka, N. Tamura, S. Tsunoda, Y. Fujita, K. Shirato, and K. Onodera. 1995. Tissue factor pathway inhibitor production by human mesangial cells in culture. J. Am. Soc. Nephrol. 6:916 (Abstract).

34. Palmier, M.O., L.J. Hall, C.M. Reisch, M.K. Baldwin, A.G. Wilson, and T.C. Wun. 1992. Clearance of recombinant tissue factor pathway inhibitor (TFPI) in rabbits. Thromb. Haemost. 68:33-36.

35. Warshawsky, I., G. Bu, A. Mast, J.E. Saffitz, G.J Broze, and A.L. Schwartz. 1995. The carboxy terminus of tissue factor pathway inhibitor is required for interacting with hepatoma cells in vitro and in vivo. J. Clin. Invest. 95: 1773-1781.

36. Osterud, B., M.S. Bajaj, and S.P. Bajaj. 1995. Sites of tissue factor pathway inhibitor (TFPI) and tissue factor expression under physiologic and pathologic conditions. Thromb. Haemostasis. 73 (5):873-875.

37. Bajaj, M.S., S.V. Rana, R.B. Wysolmerski, and S.P. Bajaj. 1987. Inhibi- 
tor of the factor VIIa-tissue factor complex is reduced in patients with disseminated intravascular coagulation but not in patients with severe hepatocellular disease. J. Clin. Invest. 79:1874-1878.

38. Bajaj, M.S., A. Ameri, M.N. Kuppuswawamy, and S.P. Bajaj. 1993. Expression of tissue factor pathway inhibitor (TFPI) and GATA-2 transcription factor by activated human monocytes. Blood. 82:343 (Abstract).

39. Van der Logt, C.P., R.J. Dirven, P.H. Reitsma, and R.M. Bertina. 1994. Expression of tissue factor and tissue factor pathway inhibitor in monocytes in response to bacterial lipopolysaccharide and phorbolester. Blood Coagul. \& Fibrinolysis. 5:211-220.

40. Lowe, M.G., S.R. Holdsworth, and P.G. Tipping. 1990. Participation of T cells in experimental anti-GBM glomerulonephritis in rabbits. Allergy and Immunology (Life. Sci. Adv.). 9:139-147.

41. Tipping, P.G., M.G. Lowe, and S.R. Holdsworth. 1988. Glomerular mac- rophages express augmented procoagulant activity in experimental glomerulonephritis in rabbits. J. Clin. Invest. 82:1253-1259.

42. Tipping, P.G., M.G. Lowe, and S.R. Holdsworth. 1991. Glomerular interleukin-1 production is dependent on macrophage infiltration in anti-GBM glomerulonephritis. Kidney Int. 39:103-110.

43. Tipping, P.G., T.W. Leong, and S.R. Holdsworth. 1991. The contribution of macrophages to glomerular tumor necrosis factor production in antiGBM glomerulonephritis in rabbits. Lab. Invest. 65:272-279.

44. Drake, T.A., J.H. Morrissey, and T.S. Edgington. 1989. Selective cellular expression of tissue factor in human tissues. Implications for disorders of hemostasis and thrombosis. Am. J. Pathol. 134:1087-1097.

45. Khouri, R.K., B. Koudsi, F. Kaiding, R.L. Ornberg, and T-C. Wun 1993. Prevention of thrombosis by topical application of tissue factor pathway inhibitor in a rabbit model of vascular trauma. Ann. Plast. Surg. 30:398-402. 